\title{
Co-Productivity as a New Value Theory in Value Chain Analysis
}

\author{
Adam Noga ${ }^{1}$, Sebastian Jarzębowski², Piotr Maciąg ${ }^{3}$
}

Submitted: 21.10.2019. Accepted: 21.03.2020

\section{Abstract}

Purpose: To incorporate a new value theory based on co-productivity into the value chain analysis. Methodology: We develop a theoretical model of co-productivity and analyze selected examples of high co-productive value chains. Our theory modifies value theories based on the classical approach (A. Smith, D. Ricardo, K. Marx), production factors of land, capital, labor, and knowledge (J.B. Clark), subjective value for the consumer (C. Menger, W.S. Jevons, and L. Walras), exchange value (A. Marshall), energy value (I. Prigogine), value added for the customer (M. Porter and P. Drucker), information value (V. Rometty), and customer attention (M. Goldhaber).

Findings: We demonstrate that the co-productivity theory deeply connects all hermeneutic sources of value creation, but more importantly, it opens opportunities for adopting future-oriented sources.

Originality: We present an original theory based on co-productivity, previously unused in logistics. We show how the theory helps to shape more effective value chains.

Keywords: co-productivity, efficiency, value theory, value chain analysis

JEL: M20

\footnotetext{
1 Kozminski University, Department of Economics, 59 Jagiellońska St., 03-301 Warsaw, Poland, e-mail: anoga@kozminski.edu, https:// orcid.org/0000-0002-6526-0001.

2 Kozminski University, Department of Economics, 59 Jagiellońska St. 03-301 Warsaw, Poland, e-mail: sjarzebowski@kozminski.edu.pl, https://0rcid.org/0000-0002-9394-577X.

3 Kozminski University, 59 Jagiellońska St., 03-301 Warsaw, Poland; pmaciag@kozminski.edu.pl, https://orcid.org/0000-0002-0035-8921.
} 


\section{Introduction}

One of the most important parts of economic theory since the eighteenth century is the theory of value. In our study, we search for the fundamental sources of value and try to appreciate the most important value theories. They all had a great inspirational impact on value chain optimization methods. However, we recently increasingly notice the attractiveness of value theory based on the phenomenon of co-productive goods (Noga, 2016). It deeply connects all hermeneutic sources of value creation. Therefore, this article seeks to introduce the concept of co-productivity in the analysis of value chains.

The article is structured as follows. The first section briefly outlines the most important value theories. The presentation and explanation of value theory based on the phenomenon of co-productive goods in the next section shows new directions in economic theory in the light of existing debates on what creates value and what determines exchange relations on the market. The third section includes three case studies that show the applicability of the co-productivity concept.

\section{Value in the Value Chain}

Although value may have different meanings, in economics, value is usually associated with the production of goods and services. Value is a deductive concept that defines the production process itself (the value of resources), its distribution, and the possible reinvestment of profits generated in the process of their distribution (Karpa, 2019). Moreover, value manifests itself as the ability to increase the efficiency of the entire industrial structure (Mazzucato, 2018).

In logistics, no final sources of value creation are sought in value chains (Porter, 1985), as is the case of the great economic theories represented by such economists as F. Quesnay, A. Smith, D. Ricardo, K. Marx, J.B. Clark, W.S. Jevons, L. Walras, C. Menger, V. Pareto, A. Marshall, K. Arrow, G. Debreu. Logistics refers at most to the concept of M. Porter and P. Drucker. According to the latter two authors, the value added for the buyer is the key source of value. Therefore, logistics takes a fairly prudent place in the great theoretical debates in economics (Chopra and Meindl, 2016). In a pragmatic way, logistics seeks to fit in the statement: "consumer is king." It also does not escape from the hard business reality in which "consumer is king" goes in hand with "cash is king," as the particular stages of the value chain must provide a financially measurable value added. The combination of these two principles allows logistics to assume the role of 
a price accepter, not a price taker or price maker, for which economists argue so strongly in the theory of competition.

However, a pragmatic and financial approach to values in logistics cannot be detached from the ultimate, fundamental, or even hermeneutic sources of values in economic theory. One must be aware that even the pragmatic and financial approach to "value added for the buyer" of M. Porter and P. Drucker, stems from the theory of subjective value of C. Menger (1871; 1950). This theory became significantly opposed to theories assuming that value is created only by work in terms of A. Smith (1776; 2003), D. Ricardo (1817) or K. Marx (1867), or by all factors of production like land, work, or capital as argued by J.B. Clark (1902).

Modern theories of value creation by energy, information, or attention begin to play an increasingly important role in the optimization of logistic value chains. The first approach (Prigogine, 2001) indicates that it is thermodynamic and ecological efficiency that plays a key role in the economy. The second approach accentuates information (Rometty, 2013), by arguing that progressive digitalization enables for the incorporation of an ever-larger part of the economy by artificial intelligence, which makes information a much stronger factor of production than energy or previously emphasized land, labor, capital, and management. However, the third approach foregrounds attention (Goldhaber, 1997) by asserting that only a special kind of information is value-creating, and it should be controlled; that is, information about information, e.g. about buyers and the attention they devote to different needs and phenomena. According to the latter, the most value is captured and characterized by the highest market value of such companies like Alphabet (Google), Microsoft, Amazon, Facebook; in other words, companies under the acronyms GAFAMA, BAT, or FAANG.

Our research seeks the fundamental sources of values in value chains by appreciating all the abovementioned theories of values from the great economic theory. However, in the analysis and optimization of value chains, we recently began to notice the attractiveness of value theory based on the co-productive goods phenomenon (Noga, 2016), which deeply connects all hermeneutic sources of value creation, also by opening opportunities for adopting future-oriented sources. The co-productivity of goods $x$ and $y$ means mutually gaining access to another good. Earlier theories of value described above are based on the phenomena of substitutability and complementarity of goods. The co-productivity of goods draws attention to the possibility of extending value chains and values for buyers, for their ability to go to higher market segments, upselling, or montée en gamme. However, the productive goods phenomenon primarily draws attention to the mutual "winding up" of the value chain in the interest of the buyer 
and his upselling. As a result, the value chain becomes more like a spiral of value created by households both from the demand side (buyer and citizen) and the supply side (employee, manager, entrepreneur, and owner). The following section presents a theory of value resulting from the co-productivity of goods for the household as a producer and buyer.

\section{Co-Productive Goods}

The co-productivity of goods ${ }^{4} x$ and $y$ is a process in which the created or acquired amount of good $y_{k}$ creates the possibility of a certain volume of good $x_{k}$, which in turn leads to the possibility of a certain volume of good $x_{l}$, in which $x_{l}>x_{k}$. Subsequently, $x_{l}$ creates access to $y_{l}$ being greater than $y_{k}$ etc. Such a positive process of co-productivity can occur until $x_{n}$ equals $y_{n}$. A further increase in any of the co-productive goods will have a negative effect, which means that it will cause a decrease in the consumption of the second good and, subsequently, also the first good. In the history of science, the phenomenon of co-productivity is excellently described by means of an experiment conducted by Joseph Priestley in 1774. The researcher placed a mouse in a closed glass container, and after a short while, it turned out that the mouse was unable to survive. Once he placed a plant (mint) in the container with the mouse, the mouse survived. Priestley discovered the life-giving connection between gases (oxygen and carbon dioxide), which humans and animals use up and give off (National Geographic, 2011). Examples of co-productivity - crucial for households to have a job - include:

- purchasing smart products, such as education services, computers, robots, ecological goods, IT applications,

- access to electronic networks, access to social networks (Granovetter, 2005; Roth, 2015),

- the possibility of renting production capacity,

- or influence on political and regulatory systems (Laffont and Tirole, 1993; goods $y$ ), and the use of assets of $H$ in creating a lucrative job and/or developing a business $(\operatorname{good} x)$.

Co-productive dependencies can exist between goods that are far from "smart," but then this co-productivity will be much smaller (shorter cycle), e.g. in the case:

\footnotetext{
4 This paper will use the term "goods" very broadly, including not only material goods but also services and even institutions, access to common goods, tariff goods, and public goods, including e.g. access to production systems (outsourcing, franchising), political systems, regulatory systems, and pension systems.
} 
- of food $(y)$ and increasing the physical strength of an employee $(x)$

- the dependency between an athlete's diet $(y)$ and his results $(x)$,

- between the purchase of a programmable machine $(y)$ and production and programming $(x)$.

However, the goods purchased or created by households will very often have no co-productive properties, meaning that they will not contribute to the creation of jobs for the buyer, although they can provide pleasure or allow survival. ${ }^{5}$

The transition from the simple definition of individual co-productive goods to more realistic choices and selections of households of entire bundles of goods will require the implementation of measuring the value of these bundles and the co-productivity between them.

Figure 1. Co-productive goods vs. complementary and substitute goods

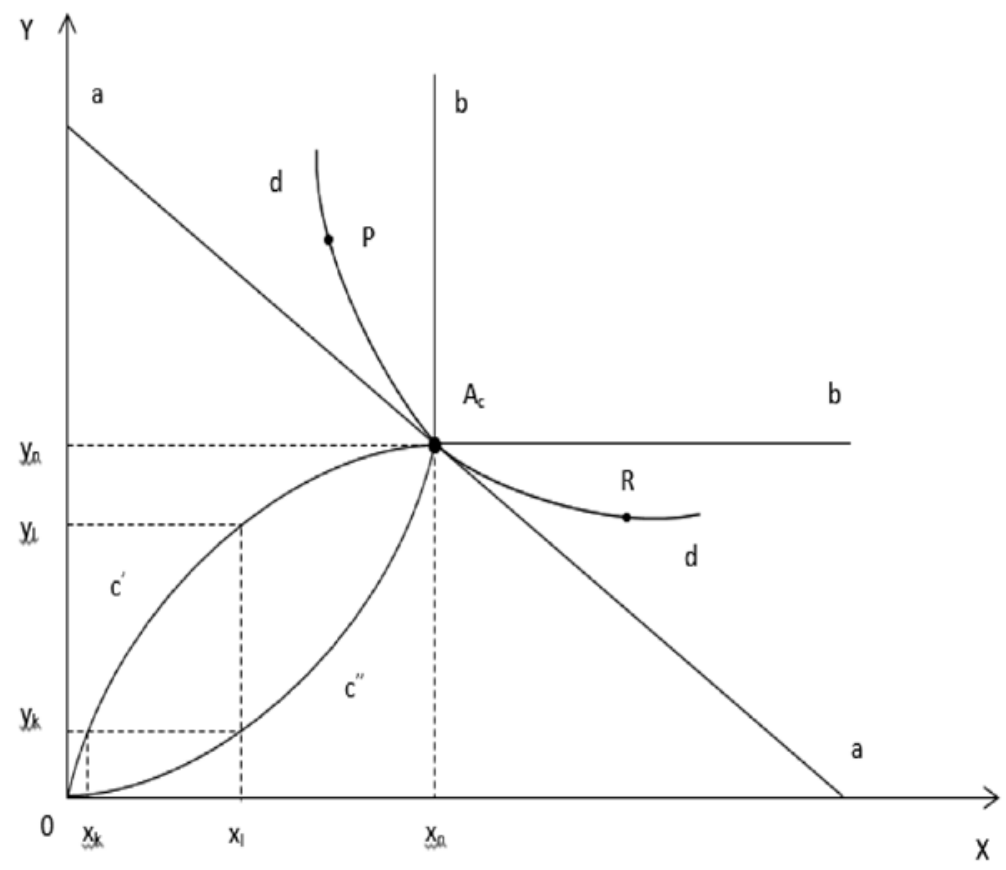

Source: own elaboration.

5 A similar method can be transferred onto other economic choices (selections), e.g. enterprises, as in the co-productivity of Union Pacific and shale gas explorers, or the choices of countries, as in e.g. the co-productivity of the national stock exchange and international financial markets. 
Figure 1 depicts the concept of co-productivity based on the example of only two goods and without their valuation. The co-productive goods $x$ and $y$ are represented by curves $c$ ' and $c$ ", while curve $a$ represents perfect substitute goods, curve $b$ perfectly complementary goods and curve $d$ (e.g. Cobb-Douglas type) substitute goods. As we know, the shape of curves $a, b$, and $d$ can be easily derived from the CES function suggested by Arrow et al. (1961).

Point $A_{C}$ in Figure 1 represents the exhaustion of positive co-productivity between goods $x$ and $y$. This point also represents the perfect substitutability and complementarity between goods $x$ and $y$. Any attempts to increase the consumption of one of the goods can: a) by reducing the consumption of the another good, goods $x$ and $y$ become substitutable for households (curve $d$ in Figure ), or b) can lead to negative co-productivity, i.e. a decrease in the consumption of both goods $x$ and $y$. By showing equal utility for households, these substitutability curves become the foundation of modern economics - on account of the Lausanne School - the foundation for the scientific explanation of the search for optimal states of economic entities and entire economies. According to Bentham's theory, a hedonistic household will prefer to be on the curves parallel to $d$, more distant from the origin. A substantial part of economic research will seek the shape of these curves - like the mentioned authors of the CES function - and use them alongside the structure of prices of goods $x$ and $y$ in order to find the optimal states of households and other entities, but also entire economies. These research studies will contain much controversy regarding, e.g., the possibilities of obtaining information about entities and their surroundings or the psychological and behavioral assumptions about entities.

Our research takes a different approach. Households do not only seek to choose a certain optimal state at specified preferences, budget constraints, prices, and the availability of goods, but they also use the drive resulting from the co-productivity of goods, i.e. their "shifting" from point 0 to $A_{C}$, and subsequently from point $A_{C}$ to further points in $A$ (Figure 2). At higher incomes and lower prices, households can increase consumption of goods $x$ and $y$, but they do not have to increase their co-productivity.

A Walras-Pareto-Menger-Jevons economy built on Bentham's entity goals will mainly focus on economic entities - not just households - shifting along the equal-utility curve $d$ in Figure 1. Points $P$ and $R$ in Figure 1 have the same utility for the entities as $A_{C}$. Thus, allocative economics emerges, explaining how entities can find optimal solutions under certain restrictions. Here, entities behave economically, or they rationally optimize their goals, which we shall refer to as universal goals, such as profit, return on assets, asset value, and asset correlation value. In contrast to universal goals, we shall 
refer to the goals that entities achieve on account of co-productivity as autonomous goals; in other words: $H$ in the economy can achieve certain goals better than enterprises, markets, or states, while enterprises achieve other goals better than $H$, markets, or states, etc. The identification of these autonomous goals and $H$ gaining access to them is the key to creating the desired work.

Households shifting to successive points $A$, their development, and especially the development of their ability to create work for themselves appears in Figure 2, which shows three paths. These paths are created by combining co-productivity curves, presented above in Figure 1. By including in Figure 2 not two but all the goods that households create and acquire, we have to move on to value analysis: axes $x$ and $y$ no longer represent the number of goods but their value, i.e. the number of goods multiplied by price (revenue, TR), which in further efficiency analysis will be equated to the assets of a household.

Figure 2. Co-productivity paths of household goods

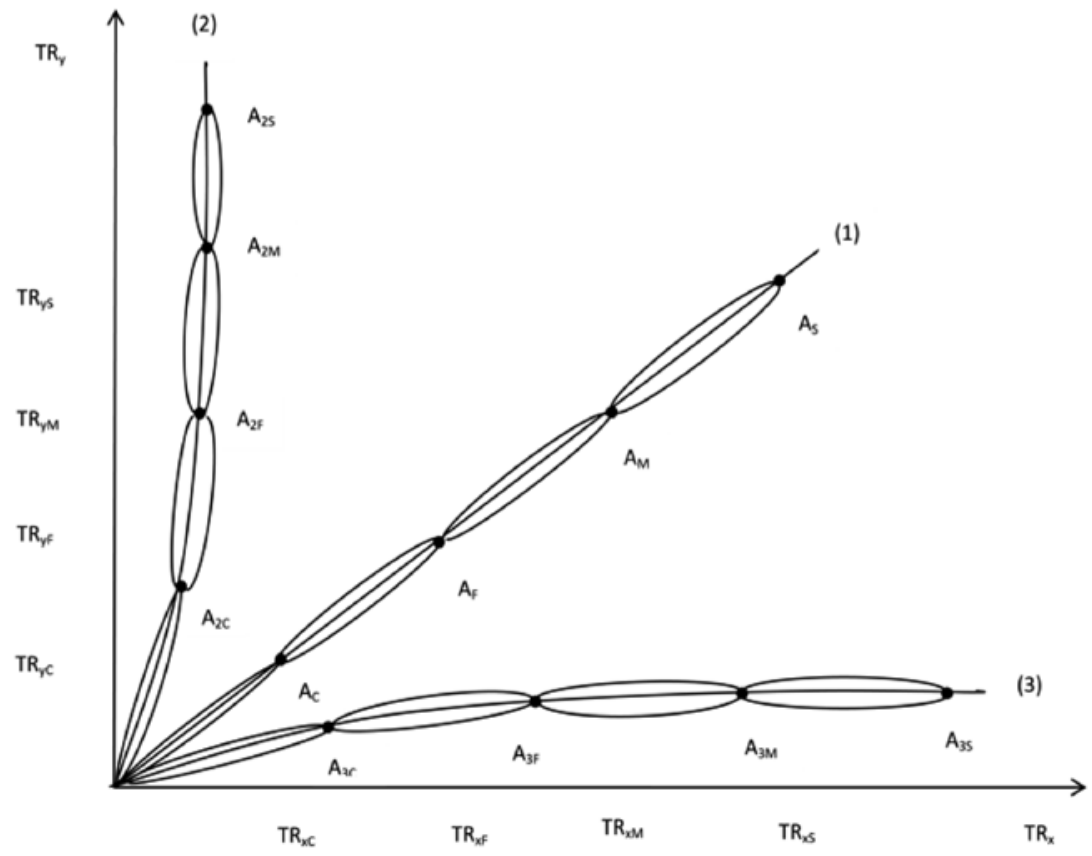

Source: own elaboration.

Despite the fact that $H$ can move along different paths in Figure 2, achieving high $A$ values, $H$ has the best chances of development - not only limited to creating work - when they move along the middle path labeled (1). Then, they have a chance to 
achieve high co-productivity between $T R_{x}$ and $T R_{y}$ : points $A_{C}, A_{F}, A_{M}$, and $A_{S}$, as the products of $T R_{x C}$ and $T R_{y C}, T R_{x F}$ and $T R_{y F} T R_{x M}$ and $T R_{y M}$, along with $T R_{x S}$ and $T R_{y S}$, demonstrate a significant increase in both $x$ and $y$. Such an increase of $x$ and $y$ in paths (2) and (3) is either much less significant or does not occur at all.

$X$ and $y$ can be co-productive with each other in an economy with four regulators. This means that they can also be co-productive with other elements: enterprises, markets, and states. For their own development and sustainable employment, households must seek to increase $x, y$, along with $w$ and $z$, which we will now define by showing households within the entire regulatory system of the economy.

In their anthropological development, households create enterprises, markets, and states, and they continue to repeat this process incessantly. Theories about enterprises, markets, and states within an economy should not ignore this fact of creation realized by households. Nonetheless, according to the structural anthropology of Claude Lévi-Strauss (1977), households are becoming a cultural product of the other three regulators, often - as already mentioned - suffering the negative consequences of the alienation of their own creations. Let us consider the regulatory system of the economy presented in Figure 3 and households' place within this system.

Figure 3. The subjective place of households within the co-productive value chain

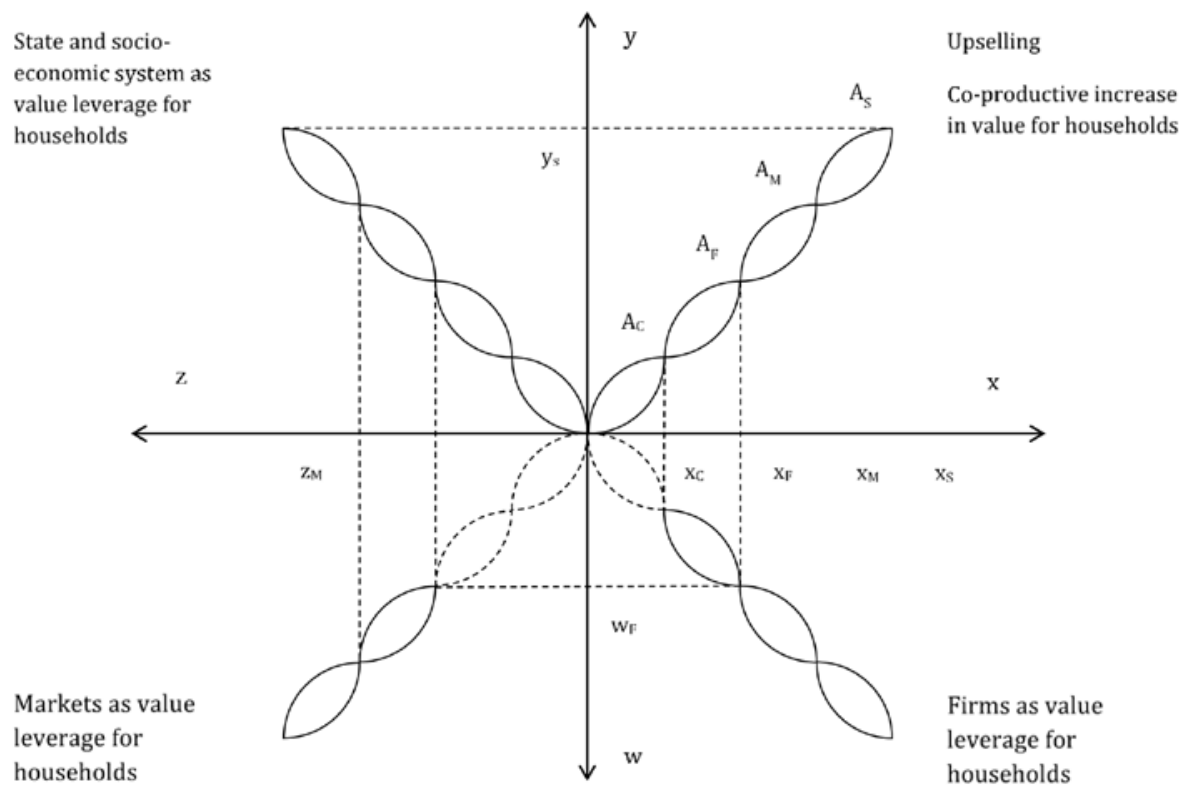

Source: own elaboration. 
Starting from point 0 , households have the possibility of reaching point $A_{C}$ in Figure 3 and achieving co-productivity between the values of bundles of goods $x_{C}$ and $y_{C}$, with the former being goods produced by households, e.g. through domestic work, and the latter being goods acquired by households from an economic system with state regulation. Reaching point $A_{F}$ will require households to start working in an enterprise, reaching point $A_{M}$ will make households enter the market, while reaching point $A_{S}$ will require households to exploit the synergies of the whole economy and society. Sections $0 A_{C}, A_{C} A_{F}, A_{F} A_{M}, A_{M} A_{S}$, and the curves connecting them will often be divided into many, invisible in Figure 3, short sections and curves, demonstrating significantly lower values of bundles of goods type $x, w, z$, and $y$, but also the co-productivity between them. In the next section, we present three case studies showing the applicability of the co-productivity concept into value chain analysis.

\section{Case studies}

As part of our research, we have already collected many interesting cases of increasing value chains according to the co-productive value theory with the key role of households. Enterprises that can most rationally combine production and consumer chains are called in our research confirms - as a wordplay on consumers and firms - and also as confirm, as the highest confirmation of the existence of a specific enterprise in the economy, which allows it to survive the largest macroeconomic crises. In this article, we will present three such cases. As the first case, we will present hotel Das Tyrol in Vienna, as a tribute to the most outstanding Austrian economist Carl Menger, born in Poland, in Nowy Sącz, constructed their influential theories of economics and management before other great Austrians like P. Drucker or J. Schumpeter.

In the theory of co-productive value, Das Tyrol can be linked with its clients in the North-East quadrant in figure 3 . The hotel and its clients remain in full co-production, thus creating further links of the value chain and raising their values together $\left(A_{C}, A_{F}\right.$, $\left.A_{M}, A_{S}\right)$. The first part of the value $\left(A_{C}\right)$ of the hotel creates by providing the most basic accommodation services. However, it uses maximum co-productiveness $\left(0, A_{C}\right)$ with the north-east quadrant in Figure 3, thanks to the fact that it was located in the museum district of Vienna. A location in this district is a natural, banal co-productive link of value usually used by all hotels. There is no novelty on the section of the value of $0, A_{C}$ beyond the theoretical one; however, this hotel tries to give that co-productive link the highest value (the longest section length $0, \mathrm{~A}_{\mathrm{C}}$ ). In relation to competing hotels, Das Tyrol tries to provide clients with a unique feeling that they are residents of the imperial district, in which the entire glitterati of Vienna lived a century ago. Hence, the 
co-productivity of the hotel with supplier companies enhances their quality. Hence, the market price increases to the price accepter level higher than the competitive price taker in a situation of strong competition, in which the hotel cannot afford a price maker.

In a similar way, the hotel creates positive co-productivity with its suppliers. Inspiration and price acceptance by the consumer allow creating long episodes of co-productive $A_{C} A_{F}, A_{F} A_{M}$, and $A_{M} A_{S}$. The first by developing the tradition of the Austro-Hungarian cuisine, the second by a personalized spa - a peculiar "Viennese bath" - and the third, absolutely sensational, by combining a co-productive hotel with a stunning art gallery in all rooms.

The second example of shaping more effective value chains - best explained by the new value theory based on co-productivity - is about energy from renewable sources. The co-productivity concept described in this paper is reflected in the cooperation between energy consumers and energy producers. Particularly noteworthy are biogas plants that can provide electricity and heat (good $y$ ) due to the use of waste (access to good $x$ ) generated in the surrounding area, such as manure, slaughterhouse waste, sewage sludge, organic waste from households, and various types of waste generated in the food production process. A typical biogas plant can process from 20,000 to 80,000 tons of manure per year, freeing farmers from the need to meet the requirements for its storage. Besides electricity and heat, biogas plants provide a fertilizer with improved properties, which boosts farmers' economic situation and helps to eliminate costly components from the value chain. Moreover, such biogas plants are usually located near cities, which enables them to provide electricity and heat surplus to local businesses at attractive prices. In Europe, many territorial self-government units use electricity from renewable sources, for instance, for street lighting. Thus, lower heating fees, lower fees for waste treatment, and sometimes lower electricity costs should also be added to the benefits for residents.

However, we should note that the functioning of a biogas plant would not be economically efficient without the participation of farmers who provide waste as a substrate that allows energy production and the local companies and residents that purchase energy, heat, and fertilizers produced by biogas plants. This leads to a perfectly positive co-productivity, in which the development of biogas plants is possible thanks to the cooperation with contractors who - through cooperation with a biogas plant - can achieve sustainable competitive advantage and build more efficient value chains.

Undeniably, the rapid development of technology in the renewable energy sector allows companies to save energy costs. Rising energy prices force managers to revise and 
reconsider energy source models in their companies. As a result, investments in renewable energy sources become a scenario that is already under implementation or consideration by many entrepreneurs. Thanks to the reduction in spending on electricity or heating, the cost of manufacturing products is lower. This enables business owners to increase expenditures allocated on investments, such as business development, innovation, or the creation of new jobs. For energy-intensive companies, any energy saving in the production process usually means a cheaper product for the customer, and thus increased competitiveness of the entrepreneur on the market.

The wide application of biogas plants in business will not only generate clean renewable energy but also reduce environmental pollution, which in the long run will positively affect the health of the whole society. As a consequence, it will help to limit the growing costs of spending on healthcare and will allow for more productive work related to improving the health of the population.

The development of renewable energy sources goes hand in hand with the hope for improving the economic situation of regions. Increasing the share of renewable energy sources in the energy production structure translates into an increase in energy security, which positively affects energy prices, stimulates the innovation process, creates new markets and new jobs, and contributes to the improvement of the quality of the environment in regions. Hence, the benefits achieved by biogas plants and companies cooperating with them can allow us to move to the next loop in our co-productivity scheme, enabling further development through the use of new assets created as a result of the cooperation.

The third case study to explain the new value theory based on co-productivity is the dairy processing value chain.

The first stage in the dairy supply chain are agricultural farms. The need for competing with high-performance agriculture in global markets and the increase of sanitary and veterinary requirements have contributed to the concentration of dairy production in Europe.

The next stage on the way from the producer to the dairy processing plant is direct or indirect transport. Direct transport is based on the receipt of raw material straight from the farm with the help of tank trucks that ensure low-temperature maintenance. Indirect transport is conducted with milk collection centers linked to a given dairy processing plant or using mobile tanks to collect and cool milk. 
The next stage in the supply chain are dairy processing plants, which are one of the largest group of enterprises operating on the European market. They are organized in the form of cooperatives, independent plants, and companies. Some dairy plants produce for the local market, some for domestic and international, by using indirect and direct distribution channels. Indirect distribution consists in moving the goods first to a high storage warehouse, and then to the shopping centers that serve wholesale customers and retail stores. Direct distribution channel consists of selling in company stores.

Dairy production is one of the most important sectors of production. Due to favorable natural conditions and the tradition of cattle breeding, some regions of Europe are particularly predisposed to develop this sector of production.

Thanks to the existence of a milk processing plant, farms can invest and develop production. On the other hand, having a raw material base, the dairy processing plant can develop the production of milk products for domestic and foreign markets. The existence of interdependence between local suppliers and the processor of milk also translates into the level of social well-being and regional development. Typically, milk production in Europe develops in those regions where the ability to create interdependencies between milk producers and processors exists. This interdependence translates into the development of the logistics sector and services supporting the dairy industry.

The co-productivity concept is reflected in the cooperation between raw milk producers: farmers and dairy processors. What is particularly noteworthy are dairy processing plants that provide dairy products (good $y$ ) due to the use of raw milk (access to good $x$ ) produced by farmers in the surrounding area.

Noteworthy, the functioning of dairy processing plants would not be economically efficient and would cause high transportation and warehousing costs without cooperation with farmers who provide raw milk. This leads to a positive co-productivity, in which the development of milk processing plants is possible thanks to the cooperation with contractors. Through this cooperation, both the suppliers and the processing plants can achieve sustainable competitive advantage and build more efficient value chains.

\section{Conclusion}

In this article, we sought the fundamental sources of value in logistics value chains. We analyzed the most important concepts of value from the history of economic theory. 
They all had a significant inspirational influence on the value chain optimization methods. However, in this article, we applied the co-productivity theory in the analysis of value chains, which deeply connects all hermeneutic sources of value creation, also opening opportunities for future-oriented sources. In the last section, we presented interesting case studies of increasing value chains that are best explained by the co-productive value theory with the key role of households.

The prerequisite for the creation of effective value chains is to regain influence on companies by households. Unfortunately, business alienation is very common, as households perform low-quality and low value-added work. Although economic theory describes various ways for such regaining of influence, households can and must count on themselves in this respect.

Value theory based on co-productivity assumes that value in the value chain depends mainly on value chain participants, while households, companies, markets, and states can only help in creating positive co-productivity by purchasing and creating ecological, intellectual, and social goods; that is, goods with the greatest co-productive potential.

\section{$\underline{\text { References }}$}

Arrow, K.J., Chenery, H.B., Minhas, B.S. and Solow, R.M. (1961). Capital-Labor Substitution and Economic Efficiency. Review of Economics and Statistics, 43, 225-250,

https://doi.org/10.2307/1927286.

Chopra, S. and Meindl, P. (2016). Supply Chain Management: Strategy, Planning, and Operation. Pearson. Clark, J.B. (1902). The Distribution of Wealth: a Theory of Wages, Interest and Profit. Macmillan.

Drucker, P. (1954). The Practice of Management. New York: Harper \& Brother.

Goldhaber, M.H. (1997). The Attention Economy and the Net. First Monday, 2.4, https://doi.org/10.5210/fm.v2i4.519.

Granovetter, M. (2005). The Impact of Social Structure on Economic Outcomes. Journal of Economic Perspectives, 19, 33-50, https://doi.org/10.1257/0895330053147958.

Karpa, W. (2019). Osobliwości inowacji medycznych. Warszawa: Poltext.

Laffont, J.J. and Tirole, J. (1993). A Theory of Incentives in Procurement and Regulation. Cambridge Mass.: The MIT Press.

Lévi-Strauss, C. (1977). Anthropologie structurale, vols. 1-2. Paris: Plon.

Marshall, A. (1920). Principles of Economics. London: Macmillan.

Marx, K. (1867). Das Kapital. Kritik der politischen Ökonomie. Hamburg, Verlag von Otto Meissner.

Maslow, A.H. (1943). A Theory of Human Motivation. Psychological Review, 50, 370-396, https://doi.org/10.1037/h0054346.

Menger, C. (1871, 1950). Principles of Economics. James Dingwall and Bert Hoselitz (Grove).

Mazzucato, M. (2018). The value of everything: Making and taking in the global economy. Hachette UK.

National Geographic (2011). The Big Idea. How Breakthroughs of the Past Shape the Future. Foreword by Timothy Ferris. Washington, D.C: National Geographic Society. 
Noga, A. (2016). Special Theory of Employment and Co-Productive Goods. Munich: Ideas-Repec.

Porter, M.E. (1985). The Competitive Advantage. New York: Free Press.

Ricardo, D. (1817). On the Principles of Political Economy and Taxation. London.

Rometty, V. (2013). The Year of the Smarter Enterprise. The Economist: World in 2014.

Roth, A.E. (2015). Who Gets What and Why. London: William Collins.

Smith, A. (2003). The Wealth of Nations. Introduction by Alan B. Krueger. New York: A Bantam Book.

Walras, L. (1874; 1926). Élémentes d'économie politique pure: ou Théorie de la richesse sociale. Lausanne: F. Rouge, Libraire-Éditeur, Paris: B, Pichon et R. Durand-Auzias. 